\title{
Orientação a Práticas Parentais: Descrição de um Programa de Intervenção Individual Breve
}

\author{
Mateus Rebelo Benites ${ }^{1}$ \\ ${ }^{1}$ Universidade Federal do Rio Grande do Sul, RS, Brasil. \\ Giovanna Nunes Cauduro ${ }^{1}$ \\ ${ }^{1}$ Universidade Federal do Rio Grande do Sul, RS, Brasil. \\ Luciana Valiente Vaz $^{1}$ \\ ${ }^{1}$ Universidade Federal do Rio Grande do Sul, RS, Brasil.
}

\author{
Érica Prates Krás Borges ${ }^{1}$ \\ ${ }^{1}$ Universidade Federal do Rio Grande do Sul, RS, Brasil. \\ Thais Selau ${ }^{1}$ \\ ${ }^{1}$ Universidade Federal do Rio Grande do Sul, RS, Brasil. \\ Denise Balem Yates ${ }^{1}$ \\ ${ }^{1}$ Universidade Federal do Rio Grande do Sul, RS, Brasil.
}

Resumo: A orientação a práticas parentais visa modificar o contexto no qual as crianças estão inseridas como forma de potencializar mudanças em seu comportamento. Esse artigo descreve uma intervenção breve de sete encontros em modalidade individual. O programa teve como finalidades principais auxiliar os cuidadores a identificar e estimular comportamentosadequados em seus filhos; ensinar novos comportamentos; incentivar a autonomia das crianças; encontrar abordagens não-agressivas para lidar com maus comportamentos; e auxiliar na organização da rotina. Como metodologia, realizou-se a descrição de três casos, exemplificando as estratégias adotadas em cada um. A análise dos casos permitiu o delineamento de características comuns entre as práticas parentais dos pais ou cuidadores. Os casos relatados neste estudo evidenciam que as famílias utilizam punição corporal, apresentam dificuldade de empatizar com a criança, possuem um estilo parental autoritário e expectativas incompatíveis com a idade das crianças. Além disso, a infância dos pais ou cuidadores apresentou forte influência no desenvolvimento de suas práticas parentais. A sobrecarga na figura materna também ficou evidente nos casos de famílias intactas. Por fim, a intervenção pode estabelecer um contato inicial da família com um serviço de psicologia, incentivando contato posterior com serviços que possam atender às demais dificuldades. A partir dos resultados examinados, conclui-se que a intervenção breve apresentou resultados positivos na mudança das relações familiares. Porém, o estudo precisa estabelecer uma medição quantitativa antes e depois da intervenção, além de uma sessão de seguimento para verificar se as mudanças são de longo prazo.

Palavras-chave: Práticas Parentais, Orientação de Pais, Intervenção Breve.

\section{Parenting Practices Orientation: Description of a Brief Individual Intervention Program}

\begin{abstract}
Orientation to parenting practices aims to modify the context in which children are inserted as a means to induce changes in their behavior. This article describes a brief sevensession individual intervention program aimed to help guardians identifying and encouraging appropriate behavior in their children, teaching new behaviors, encouraging autonomy, finding non-aggressive approaches to dealing with bad behavior, and assisting in the routine organization. The study describes three cases, exemplifying the strategies adopted in each of them. The analysis allowed the delineation of common characteristics among parental practices, indicating that families use corporal punishment, struggle in empathizing with the child, and have an authoritarian parental style and expectations that are incompatible with children's age. The results indicate that the childhood of parents and guardians had a strong
\end{abstract}


influence on the development of their parental practices. Moreover, intact families presented an overload in the maternal figure. In this scenario, the intervention can bridge an initial contact between the family and a psychology service, encouraging later contact that can attend to other family difficulties. Despite the positive changes in family relationships enabled by this brief intervention, the study requires a pre- and post-intervention quantitative measurement and a follow-up session to verify whether these changes are long-term.

Keywords: Parental Practices, Parent Guidance, Brief Intervention.

\title{
Orientación a Prácticas Parentales: Descripción de un Breve Programa de Intervención Individual
}

\begin{abstract}
Resumen: La orientación a prácticas parentales tiene por objetivo modificar el contexto en el que viven los niños como forma de potenciar cambios en su comportamiento. Este artículo describe una intervención breve de siete encuentros individuales. El programa tuvo como finalidades principales: auxiliar a los cuidadores en la identificación y estimulación de comportamientos adecuados en sus hijos; enseñar nuevos comportamientos; fomentar la autonomía de los niños; encontrar enfoques no agresivos para manejar malos comportamientos; y ayudar en la organización de la rutina. Para ello, se describió tres casos, ejemplificando las estrategias adoptadas en cada uno. El análisis de los casos permitió el delineamiento de características comunes entre las prácticas parentales de los padres/cuidadores. Los casos reportados en este estudio evidencian que las familias utilizan castigo corporal, presentan dificultad para tener empatía con el niño, poseen un estilo parental autoritario y expectativas incompatibles con la edad de los niños. Además, la infancia de los padres/cuidadores presentó una fuerte influencia en el desarrollo de sus prácticas parentales. La sobrecarga en la figura materna también estuvo evidente en los casos de familias intactas. Por último, la intervención puede establecer un contacto inicial de la familia con un servicio de psicología, incentivando un contacto posterior con servicios que puedan atender las demás dificultades de la familia. La intervención breve presentó resultados positivos en el cambio de las relaciones familiares, pero el estudio necesita establecer una medición cuantitativa pre- y posintervención y una sesión de seguimiento para verificar si los cambios son a largo plazo.
\end{abstract}

Palabras clave: Prácticas Parentales, Orientación de Padres, Intervención Breve.

\section{Introdução}

Entende-se parentalidade como o cuidado e a educação da prole desde a concepção até a independência, sendo um processo comum a todos os mamíferos. A parentalidade tem sido vista como uma fonte importante de variabilidade ambiental e uma das maiores influências no desenvolvimento inicial. Dentre os mamíferos, os humanos representam o grupo em que a parentalidade é ainda mais determinante, devido, principalmente, ao período prolongado de imaturidade física e intelectual dos bebês. É importante ressaltar que o exercício da parentalidade não se limita aos pais biológicos da criança, mas inclui todo e qualquer cuidador responsável por responder às necessidades do infante (Bjorklund, Yunger, \& Pellegrini, 2002).

Uma característica essencial da parentalidade se fundamenta na relação estabelecida entre cuidador e criança, na qual cabe ao cuidador o papel de facilitador de comportamentos adequados à idade e ao contexto em que a criança está inserida. Nessa função, tem-se as práticas parentais como ferramentas-chave no estabelecimento de comportamentos em seus filhos (Reppold, Pacheco, \& Hutz, 2005). Considerados aspectos mais variáveis da parentalidade, as práticas parentais são técnicas utilizadas pelos pais a fim de 
influenciar determinadas respostas das crianças em situações específicas (Blisset, 2011). Dessa maneira, os pais são vistos como balizadores dos comportamentos dos filhos por meio das técnicas que optam por utilizar como resposta às atitudes da criança ou como estímulo para a realização de alguma tarefa (Pacheco, Silveira, \& Schneider, 2008). Podem ser considerados exemplos de práticas parentais: abaixar-se à altura da criança em um momento de birra e conversar em tom de voz normal ou gritar com a criança quando ela quebra algo dentro de casa.

A relação entre o cuidador e a criança é permeada por aspectos do cuidador, por exemplo, histórico de doenças mentais (depressão perinatal e pós-parto, ansiedade etc.), predisposições genéticas e memórias ou representações das relações estabelecidas com seus próprios cuidadores (práticas parentais aprendidas). Por outro lado, aspectos como o temperamento da criança, bem como a presença ou ausência de deficiências físicas ou mentais, aspectos emocionais ou doenças crônicas são exemplos de características infantis que podem influenciar o tipo de relação que se estabelecerá (Poehlmann-Tynan et al., 2015; Shah, Clements, \& Poehlmann, 2011; Shah, Sobotka, Chen, \& Msall, 2015).

Além dos aspectos individuais, devem ser considerados os aspectos socioculturais da relação. Nesse contexto, a família aparece como o meio pelo qual valores e fatores culturais são passados para a criança (French, 2002). Portanto, a maneira como a criança vai interagir com o meio será perpassada por esses diferentes fatores, podendo resultar em comportamentos adaptativos e funcionais ou não (Shaffer, Lindhiem, Kolko, \& Trentacosta, 2013). Ambientes familiares estressantes ou negligentes, permeados por atitudes parentais inadequadas ou pejorativas recorrentes para com a criança, tendem a influenciar a ocorrência de comportamentos disruptivos (Zahrt \& MelzerLange, 2011).

O contexto em que a criança está inserida facilita não apenas o desenvolvimento de comportamentos, como também sua manutenção, uma vez que as atitudes parentais influenciam diretamente a conduta das crianças, além de servirem de modelo. Conflitos no ambiente familiar, naturalização de comportamentos agressivos, disciplina e monitoramento parental instáveis ou pobres aumentam a propensão ao desenvolvimento de comportamentos externalizantes, como a agressividade. A presença consistente de disfunção no lar - desavenças conjugais, por exemplo - tende a naturalizar comportamentos dessa ordem, tornando a agressão parte do repertório comportamental de muitos jovens de famílias com altos níveis de disfunção (Smokowski, Rose, Bacallao, Cotter, \& Evans, 2017).

São crescentes as evidências da influência da relação entre práticas parentais desfavoráveis e problemas comportamentais em crianças e pré-adolescentes. Esses achados têm levado ao desenvolvimento de intervenções que englobam diferentes aspectos do surgimento e manutenção de comportamentos disfuncionais infanto-juvenis (Lochman, 2016; Muratori et al., 2017; Patterson, Chamberlain, \& Reid, 2016). O treino parental tem sido amplamente utilizado com o objetivo de modificar o contexto em que a criança está inserida, além dos comportamentos apresentados por ela. Essas intervenções se baseiam na premissa de que a mudança de comportamento da criança não será tão efetiva ou mantida a longo prazo quando não for acompanhada de treino parental (Henneberger, Varga, Moudy, \& Tolan, 2016).

Ainda que sejam consideradas cruciais para a mudança de comportamentos indesejados nas crianças, intervenções direcionadas aos cuidadores têm limitações importantes. A escolha por modalidade grupal ou individual, a participação de um ou dois cuidadores principais, a realização das atividades em casa ou na clínica são dilemas essenciais da implementação de programas de orientação e/ou treino parental. Também se considera que o nível de engajamento dos cuidadores no tratamento pode interferir na eficácia do programa. Um dos principais problemas enfrentados pelos profissionais na implementação de programas dessa ordem tende a ser o entendimento dos cuidadores quanto à finalidade das atividades. Para alguns, o simples convite para participar de um programa significa questionar suas capacidades, podendo apresentar maior resistência (Barkley, 2013).

O entendimento errôneo dos propósitos da orientação pode levar a equívocos no manejo das situações trazidas pelos participantes, afetando diretamente os resultados. O esclarecimento da finalidade do programa se torna essencial para amenizar alguns dos obstáculos citados acima (Barkley, 2013). Treinar ou orientar cuidadores de crianças com problemas de comportamento facilita que as intervenções realizadas com a criança se mantenham a longo prazo. Além disso, pode auxiliar no entendimento dos pais sobre a relação entre os comportamentos dos filhos 
e as práticas por eles adotadas. Ademais, os programas buscam melhorar a qualidade da relação familiar, favorecendo a aceitação das práticas parentais pela criança (Breitenstein, Shane, Julion, \& Gross, 2015; Coatsworth et al., 2015; Law, Neihart, \& Dutt, 2017).

Dentre os modelos utilizados na literatura, as intervenções realizadas individualmente ganham destaque devido à possibilidade de personalização da intervenção. Além disso, os pais parecem se beneficiar mais de programas individualizados do que em grupo (Barkley, 2013). A adaptação do programa de orientação parental para os problemas específicos das crianças tende a ser mais eficaz do que modelos interventivos padronizados.

Considerando as vantagens dos programas de orientação a práticas parentais individualizados e a escassez de artigos brasileiros que detalhem as estratégias utilizadas nessas intervenções, o presente estudo tem como objetivo apresentar um modelo desse tipo de programa, descrevendo os procedimentos utilizados e as temáticas abordadas. Para isso, serão apresentados três casos, exemplificando as estratégias adotadas em cada um.

\section{Método}

O Programa de Orientação de Práticas Parentais (Propap) se originou das demandas do Centro de Avaliação Psicológica (CAP) da Universidade Federal do Rio Grande do Sul (UFRGS). O objetivo foi fornecer aos usuários do CAP orientações relacionadas ao manejo de crianças com problemas de comportamento. Além disso, o Propap surgiu da tentativa de preencher uma lacuna algumas vezes deixada pela psicoterapia individual: a modificação do ambiente da criança para a melhora de comportamentos disruptivos.

\section{Participantes}

Participaram do Propap no primeiro semestre de 2017 seis famílias. No presente artigo, descreveremos três casos: Alberto, pai de Antônio (15 anos); Carlos e Cecília, pais de Cristiano (18 anos), Caroline (16 anos) e Camila (10 anos); e Silvia e Sérgio, pais de Sandro (11 anos) e Sabrina (6 anos). Os nomes utilizados são fictícios, visando preservar o anonimato dos participantes. Todos os casos foram encaminhados para a orientação de práticas parentais após a realização de avaliação psicológica de um dos filhos no CAP da
UFRGS. As demandas de cada caso foram bastante singulares, conforme a dificuldade de cada família. De forma geral, envolviam problemas de relacionamento familiar e de comportamento dos filhos.

\section{Procedimentos}

O Propap é um programa organizado em sete encontros com temáticas pré-estabelecidas. Esses encontros ocorrem semanalmente e têm duração aproximada de uma hora. Ainda que sejam pré-estabelecidos, a quantidade e o conteúdo das sessões podem variar a fim de atender as demandas de cada caso. Esse modelo de intervenção foi baseado em outros programas de treinamento de pais de terapia cognitivo-comportamental (Caballo, 2005; Caminha \& Caminha, 2011; Pardo e Carvalho, 2012), incluindo elementos da teoria do apego (Cassidy \& Shaver, 2008; Siegel, 2012) e da teoria sistêmica (Carter \& McGoldrick, 1995; McGoldrick, Gerson, \& Petry, 2012). Os terapeutas que realizam a intervenção são alunos de graduação em estágio de ênfase em processos clínicos, supervisionados por psicólogos com experiência clínica. Todos os participantes assinaram Termo de Consentimento Livre e Esclarecido (TCLE) autorizando a utilização dos dados com a finalidade de pesquisa.

O programa teve como finalidades principais auxiliar os cuidadores a identificar e estimular comportamentos adequados em seus filhos; ensinar novos comportamentos; incentivar a autonomia das crianças; encontrar abordagens não-agressivas para lidar com maus comportamentos; e auxiliar na organização da rotina. Para isso, o Propap foi organizado conforme descrito a seguir.

\section{Descrição das sessões}

Não foi estabelecido um número fixo de sessões, uma vez que a exploração de cada temática pode levar mais de uma sessão. No entanto, o primeiro encontro sempre se inicia com o primeiro tema e os demais são abordados sempre na ordem proposta, com exceção da temática livre, que é inserida de acordo com a necessidade de cada família.

\section{Tema 1:Apresentação da intervenção e definição dos objetivos}

Objetivos: identificar e elencar dificuldades percebidas pelos cuidadores no trato diário com as 
crianças para, a partir disso, definir os objetivos a serem alcançados durante a intervenção.

Procedimentos: o encontro inicial serve para elucidar a finalidade do programa e identificar junto aos cuidadores as dificuldades percebidas no manejo com seus filhos. Para isso, são utilizadas técnicas de entrevista semiestruturada sobre práticas parentais, explicações sobre o funcionamento do programa e aplicação de instrumento de avaliação de desenvolvimento infantil (Goodman, 1997; Woerner et al., 2004).

\section{Tema 2: Experiência dos pais com seus cuidadores}

Objetivo: explorar as experiências que os participantes vivenciaram com seus próprios cuidadores na infância e identificar as práticas nelas aprendidas.

Procedimentos: uma entrevista semiestruturada baseada na adult attachment interview (Cassidy \& Shaver, 2008) é utilizada para guiar a conversa durante a sessão. A técnica de organização do genograma também é aplicada com o objetivo de compreender a estrutura familiar.

\section{Tema 3: Rotina e autonomia}

Objetivo: conhecer a rotina da família, identificar as dificuldades e auxiliar em possíveis ajustes para um melhor funcionamento cotidiano.

Procedimentos: é proposto aos pais que construam uma tabela da rotina familiar a fim de melhorar a visualização de todos os compromissos diários do grupo. A partir da tabela, são investigados detalhes a respeito da organização cotidiana geral (horários de refeições, atividades extracurriculares, horário que a criança vai dormir etc.); quais as atividades domésticas realizadas por cada membro da família (lavar a louça, arrumar o quarto, varrer a casa etc.).

Questões referentes à divisão de responsabilidades são abordadas, apresentando aos pais uma tabela com diferentes atividades que podem ser realizadas pelas crianças conforme a faixa etária. Ao final da sessão, é entregue aos pais uma tabela de monitoramento de bons comportamentos dos filhos, para ser preenchida como tarefa durante a semana, que será usada na sessão seguinte.

\section{Tema 4: Práticas parentais e comportamentos adequados}

Objetivo: explorar quais comportamentos adequados a criança já realiza e identificar aqueles que os pais ainda esperam dos filhos, para que os cuidadores aprendam a ensinar e estimular tais comportamentos.

Procedimentos: a partir da tarefa de casa da sessão anterior, utiliza-se uma abordagem psicoeducativa para auxiliar os pais na manutenção dos comportamentos considerados adequados. São trabalhados os conceitos de modelagem, reforçamento e recompensas, traduzidos em uma linguagem acessível para a população e aplicados à realidade da família. Além disso, são trabalhadas expectativas em relação a quais comportamentos são esperados para a faixa etária da criança.

\section{Tema 5: Comportamentos inadequados}

Objetivo: identificar o que os pais entendem por comportamentos desadaptativos da criança, verificar as práticas utilizadas com a criança no momento que ela apresenta tais comportamentos e auxiliar os cuidadores a adotarem práticas educativas mais saudáveis e protetivas para a criança.

Procedimentos: o terapeuta se vale de práticas psicoeducativas para ensinar aos cuidadores questões pontuais sobre o momento certo para disciplinar, o papel dos pais enquanto exemplo para as crianças, a importância da validação de sentimentos e como usar de extinção e punição nas situações de difícil manejo. Busca-se entender, ainda, os antecedentes e as consequências dos comportamentos considerados difíceis, com o objetivo de, em um trabalho colaborativo, pensar estratégias viáveis e úteis.

\section{Tema 6: Sessão livre}

Objetivo: abordar algum assunto específico relacionado ao caso que seja de interesse dos cuidadores.

Procedimentos: o assunto abordado na sessão livre é pré-definido com os pais ao longo das sessões anteriores. A partir disso, o terapeuta elabora o material necessário para psicoeducação sobre o tema. Alguns exemplos de assuntos seriam: agressividade, sexualidade e relação com a escola. Em virtude da variabilidade dessa temática ao longo das intervenções e impossibilidade de comparação entre as diferentes famílias atendidas, o Tema 6 não será objeto de análise.

\section{Tema 7: Encerramento}

Objetivo: retomar os aprendizados dos cuidadores ao longo da intervenção e fornecer um material personalizado sobre os temas abordados ao longo das sessões. 
Procedimentos: são retomados os principais pontos abordados na intervenção e destacadas as estratégias utilizadas pelos pais. Visando a generalização dos aprendizados em sessão para o dia a dia, o terapeuta entrega aos cuidadores um memorial impresso resumindo a intervenção com algumas estratégias úteis e pontuais. Para finalizar, são feitas perguntas sobre: a) o que mudou; b) o que começou a mudar, mas ainda poderia melhorar; e c) o que não se alterou. Pede-se, ainda, um feedback dos cuidadores sobre a intervenção. Nessa sessão, também é combinada a entrevista de manutenção a ser realizada três meses após o final da intervenção.

\section{Resultados}

\section{Caso 1: Alberto (pai de Antônio)}

Demanda: Antônio realizou avaliação psicológica no CAP em razão de dificuldades escolares e comportamentos agressivos em diferentes contextos. Após o término do processo de avaliação, o menino foi encaminhado para psicoterapia individual e seu pai, Alberto, para a intervenção no Propap.

História clínica: Antônio (15 anos) morou com os pais (Alberto, 39 anos, e Andréia, 37 anos) até os 13 anos. Após esse período, residiu um pouco com cada um. No período da intervenção, Antônio estava morando com seu pai. A mãe possui diagnóstico de transtorno afetivo bipolar e realizou três tentativas de suicídio. Alberto admitiu ser agressivo com a mulher e o filho, tendo cometido violência física contra eles (inclusive quando Andréia estava grávida). As brigas entre pai e filho eram constantes, pois Alberto não sabia lidar com os comportamentos desafiadores de Antônio. Esse funcionamento familiar propiciava que pequenos conflitos terminassem em violência.

\section{Tema 1: Apresentação da intervenção e definição dos objetivos}

Os objetivos do programa foram pensados com o pai e o filho. Alberto criou uma lista durante o atendimento e Antônio contribuiu com ideias em uma lista trazida pelo pai em outro momento. Os objetivos destacados foram: a) criar uma rotina diária de afazeres para Antônio; b) melhorar a convivência entre os dois; c) aumentar o autocontrole de Alberto para lidar com as situações de conflito; d) não chamar a atenção de Antônio constantemente; e e) não dar tanta importância para pequenas coisas do cotidiano dos dois.

\section{Tema 2: Experiência dos pais}

Alberto foi criado pela mãe, que recebeu o diagnóstico de câncer quando ele era adolescente. Alberto admitiu, com arrependimento, que não se preocupava com a situação de saúde dela. Ela faleceu dois anos após o diagnóstico. Alberto conseguiu perceber que seu filho estava apresentando comportamento parecido com o dele em relação aos pais, sem empatia com os problemas familiares. Antônio exigia que Alberto lhe desse bens materiais independentemente da situação financeira da família. Após a discussão de algumas estratégias interventivas, Alberto começou a estabelecer limites ao filho, uma vez que percebeu que suas ações permissivas eram resultado de sentimentos de culpa.

\section{Tema 3: Rotina e autonomia}

Alberto tentava estabelecer com Antônio uma rotina com regras e limites, entretanto, dificilmente Antônio cumpria os combinados. Nessas tentativas, o pai acabava exagerando em alguns aspectos, como insistir em chamar atenção muitas vezes por uma única coisa, ser muito rígido, perder o controle e agir de forma agressiva. Ainda, utilizava recompensa monetária para que o filho realizasse as tarefas de casa. Após a explicação, Alberto compreendeu que oferecer dinheiro não era a melhor estratégia de reforçamento. Além disso, foram discutidas outras estratégias para que ele pudesse estabelecer regras, limites e cobranças compatíveis com a idade e comportamentos do filho. Após a discussão do tema, Alberto conseguiu fazer que Antônio seguisse a rotina proposta de maneira parcial.

\section{Tema 4: Práticas parentais e comportamentos adequados}

Alberto reconheceu ter dificuldade em lidar com a falta de controle nos momentos de raiva, principalmente porque não sabia lidar com o sentimento de outra maneira que não a violência. Ele admitiu ter agredido o filho em alguns episódios. Apesar disso, tinha consciência de que seus atos violentos serviam como exemplo para que Antônio lidasse com seus problemas da mesma maneira. Em psicoeducação, foi sugerida a estratégia de sair do ambiente de conflito para se acalmar, para, depois, retornar e conseguir manter um diálogo com o filho. Alberto teve dificuldade de implementar a estratégia, 
pois acreditava que, ao se afastar, estaria dando razão ao filho. Foi discutido com ele a inverdade dessa afirmação e a importância de ele entender que não bater no filho não significava dar razão a Antônio.

\section{Tema 5: Comportamentos inadequados}

Alberto tinha dificuldade em perceber que alguns comportamentos relatados por ele como maus não eram necessariamente ruins, mas diferentes do que ele esperava. Algumas situações incluíam o tempo que Antônio demorava para realizar tarefas ou combinações, como jantar, tomar banho e arrumar o quarto. Outras se referiam à desobediência de alguma regra colocada pelo pai, como não parar de jogar videogame de acordo com o horário combinado. Foram retomadas as expectativas de Alberto quanto à mudança no comportamento do filho, fazendo um paralelo entre os comportamentos que eram desadaptativos e os que estavam dentro da autonomia de escolha do adolescente. Apesar de entender a diferença a partir da apresentação de exemplos, Alberto teve muita dificuldade de aceitar que algumas divergências ocorriam em virtude das características pessoais de cada um.

\section{Tema 7: Encerramento}

Ao final da intervenção, Alberto procurou a psicoterapeuta do filho para terapia familiar. Diante da negativa de Antônio, Alberto combinou que eles alternariam as consultas durante o mês. Foi ressaltado que a terapia individual seria importante para que cada um tivesse seu espaço. Quanto à avaliação dos resultados da intervenção, Alberto considerou que, apesar de continuar havendo episódios de descontrole, ele passou a questionar sua agressividade. Os problemas de rotina apresentaram progressos, mas ainda precisavam melhorar. Por fim, Alberto admitiu que estava cansado de tentar fazer com que Antônio se tornasse mais responsável. Em relação à escola, decidiu que ajudaria o filho com aulas de reforço, mas permitiria que ele vivenciasse as consequências de não estudar.

\section{Caso 2: Cecília e Carlos (pais da Camila, Caroline e Cristiano)}

Demanda: Camila realizou avaliação psicológica no CAP em razão de dificuldades na escola, comportamento infantilizado para a idade e co-leito com o pai. Após o início da avaliação, Cecília e Carlos foram convidados a participar da intervenção do Propap.
História clínica: Carlos (40 anos) e Cecília (40 anos) são pais de Cristiano (18 anos), Caroline (16 anos) e Camila (10 anos). A família enfrentava diversos conflitos em casa, principalmente entre $o$ pai e o filho mais velho. Cristiano estava envolvido com tráfico de drogas e estaria ameaçado de morte. Com a filha mais nova, o problema era o co-leito. Camila dormia no quarto dos pais junto com Carlos enquanto Cecília dormia no quarto das filhas junto com Caroline. Camila apresentava problemas de aprendizagem, sofria bullying dos colegas e fazia birra na hora de ir para a escola. Quanto à Caroline, os pais a percebiam como distante da família.

\section{Tema 1:Apresentação da intervenção e definição dos objetivos}

Os objetivos estabelecidos pelos pais foram: a) fazer com que Camila dormisse no próprio quarto; b) encontrar maneiras de lidar com as birras quanto à escola; c) saber lidar melhor e aceitar a adolescência de Caroline; e d) fazer Cristiano cumprir as regras familiares.

\section{Tema 2: Experiência dos pais}

Carlos foi criado pela avó. Seu pai era alcoolista e sua mãe não participou da criação. Na infância, não recebeu muitos limites ou regras. Ele não fez qualquer conexão entre sua maneira de disciplinar os filhos e a forma como foi criado pela avó. Carlos acreditava que suas práticas eram apoiadas por sua experiência no exército. Para ele, os filhos não podiam ter privacidade total (chegou a instalar um programa no computador para espionar o que faziam). Como explicação para esse controle, Carlos afirmou ter medo de assaltos, morte e estupros.

Cecília foi criada pelo pai e pela mãe, que eram rígidos e agressivos com ela. Ela admitiu que sua experiência influenciava na maneira como estava criando seus filhos, pois buscava oferecer amor e compreensão. Cecília discordava da rigidez do marido, causando muitos conflitos entre o casal. Carlos culpava a esposa pelos problemas familiares, bem como diminuía a importância de sua opinião. Foi explicada a importância da coparentalidade e de um diálogo para a disciplina unificada. Ambos concordaram com essa necessidade, porém, ninguém se mostrou disposto a ceder.

\section{Tema 3: Rotina e autonomia}

Cecília estava sobrecarregada com as atividades domésticas, ao passo que Carlos não cumpria com 
nenhuma. Foi esclarecida a importância da divisão das tarefas da casa entre todos, incluindo os filhos. Para isso, foram apresentadas tarefas que as crianças conseguiriam fazer em cada idade. Os dois combinaram que proporiam aos filhos que escolhessem uma atividade do lar para ter como sua responsabilidade. Carlos também se dispôs a assumir algumas tarefas. Quanto aos conflitos, Carlos contou que costumava se irritar com Cristiano porque ele usava todas as toalhas da casa e as deixava espalhadas. Foi indicado que os pais estipulassem ao filho o limite de uma toalha por dia.

\section{Tema 4: Práticas parentais e comportamentos adequados}

Cecília conseguiu identificar alguns comportamentos adequados dos filhos, enquanto Carlos teve dificuldade nessa tarefa. Para ele, as mudanças seriam insignificantes tendo em vista que não aconteciam em sua presença. Foi explorado com os pais o papel do elogio no reforço dos bons comportamentos. Cecília disse que costumava elogiar os filhos sempre que possível. Já Carlos afirmou elogiar somente Camila e Caroline. Discutiu-se sobre a possibilidade de oferecer uma atividade em família como recompensa para os bons comportamentos. Ambos se interessaram pela estratégia.

\section{Tema 5: Comportamentos inadequados}

Nesse tema, foi abordada a necessidade de os pais concordarem quanto às regras passadas aos filhos. Cecília e Carlos admitiram não haver diálogo entre eles em razão de uma enorme dificuldade de conversar sem discutir. Assim, eles conseguiram perceber o quanto isso prejudicava sua autoridade frente aos filhos. Cecília explicou que atuava como mediadora de conflitos entre eles e Carlos. Carlos disse que não acreditava que seria possível mudar esse ponto, principalmente entre ele e Cristiano, pois as possibilidades de diálogo estariam esgotadas. Foi indicado que a família procurasse terapia familiar, tendo em vista que muitas demandas trazidas por eles não seriam o foco da intervenção de orientação aos pais.

\section{Tema 7: Encerramento}

Os pais conseguiram identificar melhoras significativas nas questões com as filhas. Carlos admitiu que parte da responsabilidade sobre a situação atual da família seria dele. No início da intervenção, ele acreditava que tudo seria culpa da esposa. Ele contou que já havia buscado um local para iniciar a terapia familiar.

$\mathrm{Na}$ avaliação dos resultados da intervenção, os pais concordaram que aconteceram diversos avanços. Caroline estava ajudando mais em casa e aceitando dividir o quarto com a irmã. Camila estava conseguindo dormir no próprio quarto e ajudando a mãe com algumas tarefas domésticas. Cristiano estava se ajustando à questão das toalhas, saindo menos e chegando mais cedo em casa. Cecília ressaltou que alguns pontos ainda precisavam melhorar, por exemplo, o filho continuava não avisando aos pais aonde iria, bem como mantinha as más companhias. Carlos não viu melhoras em sua relação com Cristiano, além de menosprezar o avanço dele a partir das combinações realizadas.

\section{Caso 3: Silvia e Sérgio (pais de Sabrina e de Sandro)}

Demanda: Sandro realizou avaliação psicológica no CAP por dificuldades na escola. Foi concluído que o menino não tinha a estimulação adequada em casa. Por esse motivo, os pais foram encaminhados ao Propap. Como demanda dos pais, a urgência maior eram os problemas de comportamento de Sabrina, que tinha dificuldade em seguir regras, era agressiva e tinha comportamentos sexualizados que a mãe julgava inadequados.

História clínica: Silvia (35 anos) e Sérgio (42 anos) são pais de Sandro (11 anos) e Sabrina (6 anos). A menina foi diagnosticada com epilepsia, tendo danos no córtex pré-frontal devido às crises convulsivas. Sabrina tinha acompanhamento com neurologista, psiquiatra e psicólogo. Para a mãe, o problema neurológico tinha relação com os problemas de comportamento da menina. Sérgio não tinha grande participação na educação e criação das crianças, sendo atuante somente em momentos de maior dificuldade. $\mathrm{Na}$ intervenção, participou a partir do terceiro tema.

\section{Tema 1:Apresentação da intervenção e definição dos objetivos}

Silvia estabeleceu como objetivos: a) aprender a lidar com a questão da sexualidade da filha; b) encontrar maneiras de manejar a agressividade de Sabrina; e c) saber estimular o cumprimento das regras e limites dados aos filhos. 


\section{Tema 2: Experiência dos pais}

Silvia foi criada pelo pai e pela mãe. Seu pai a ridicularizava por sua aparência, a comparando com a irmã que, segundo ele, era mais bonita. Sua mãe era bastante agressiva, frequentemente praticando atos de violência física contra ela. Silvia reconheceu que nunca foi estimulada a pensar em sua própria beleza e feminilidade, pois foi criada como menino. Para aliviar as frustrações, se automutilava. Durante a intervenção, afirmou que se esforçava muito para não ser como sua mãe. Não agredia fisicamente os filhos, porém, não validava a expressão de sentimentos, principalmente relacionados à Sabrina. Silvia não sabia lidar com os desejos da filha em ter cabelo comprido, se arrumar e ter interesse por meninos da sua turma. Sem perceber, estava repetindo os comportamentos de seus pais.

\section{Tema 3: Rotina e autonomia}

Pela primeira vez, Sérgio esteve presente. Foi discutido com o casal sobre a importância da divisão justa das tarefas domésticas dentro das capacidades de cada um. Ambos mostraram disposição em dividir as atividades com os filhos e fazer com que eles tivessem mais autonomia. Silvia ressaltou que costumava ditar as regras e resolver os conflitos sozinha, tendo em vista que Sérgio chegava tarde, cansado e sem paciência para atender as crianças. Foi sugerido que o pai combinasse o momento da brincadeira após um horário de descanso, de modo que todos saberiam quando o pai estaria disponível para os filhos.

\section{Tema 4: Práticas parentais e comportamentos adequados}

Silvia conseguiu elencar diversos pontos positivos sobre os filhos, por exemplo, quando Sabrina dá beijos de bom dia e Sandro ensina a irmã a jogar bola. Ela pareceu entender que a filha não seria sempre agressiva e que, sendo auxiliada a lidar com sua raiva, Sabrina, provavelmente, poderia encontrar maneiras mais adaptativas de processas essas emoções.

Em suas práticas parentais, os pais costumavam dar avisos que não cumpriam. Foi indicado que eles estabelecessem regras e consequências realistas, dando preferência para estratégias com uma lógica positiva, como: "quando você fizer isso, vai poder fazer aquilo".

\section{Tema 5: Comportamentos inadequados}

Silvia percebeu que adotava práticas destoantes entre os filhos. Com Sandro, tentava compreender o motivo dos seus comportamentos e conversava sobre o que estava acontecendo. Com Sabrina, focava na disciplina e na punição, sendo menos compreensiva. A menina apresentava baixa tolerância à frustração e se batia quando seus erros eram apontados. Foi explicado que o ideal seria acolher os sentimentos dela e, se necessário, tentar contê-la, mas só disciplinar e conversar sobre o que aconteceu após ela ter se acalmado. Também foi discutida a importância de validar as expressões emocionais de Sabrina para que ela se sentisse à vontade para conversar com a mãe, o que não ocorria.

\section{Tema 6: Psicoeducação: temperamento infantil e desregulação emocional}

Foi realizada psicoeducação sobre temperamento infantil e sua relação com as práticas parentais, destacando as diferenças entre os filhos e como determinadas práticas poderiam ser mais efetivas com um deles e menos com outro. Discutiu-se como as crianças respondem de modo diferente, dependendo de seu temperamento, e que é importante que os pais estejam atentos e alinhem suas práticas às necessidades de cada criança. Foi realizada uma discussão sobre as diferenças entre Sabrina e Sandro e como os pais poderiam adequar suas práticas para cada um dos filhos.

\section{Tema 7: Encerramento}

Na entrega do memorial, Silvia disse que Sérgio estava mais presente e participativo nas tarefas domésticas e todos os combinados estavam sendo seguidos. Além disso, ela contou que estava pensando em voltar a estudar e trabalhar.

Quanto à avaliação dos resultados da intervenção, os pais consideraram positivas as estratégias ensinadas. Estavam conseguindo ser mais firmes e efetivos nas regras e limites dados aos filhos, o que contribuía bastante para a organização familiar. Sabrina estava menos agressiva, porém, ainda com dificuldade em expressar seus sentimentos de forma mais adaptativa.

\section{Discussão}

O presente estudo teve como objetivo apresentar a intervenção realizada pelo Propap a partir das 
diferentes temáticas trabalhadas com os três casos descritos acima. A análise dos casos permite o delineamento de características comuns entre as práticas parentais dos pais ou cuidadores: incidência de punição corporal, estilos parentais autoritários, dificuldades em lidar com as transições do ciclo vital da família e comportamentos baseados nas práticas parentais que seus próprios pais ou cuidadores utilizaram, seja na forma de repetição, seja na forma de oposição.

As características levantadas são congruentes com o que se encontra na literatura sobre dificuldades parentais. Podemos verificar alta incidência de punições corporais na população brasileira (Brandenburg \& Weber, 2005; Weber, Viezzer, \& Brandenburg, 2004) e sua correlação tanto com estilos parentais autoritários (Cecconello, Antoni, \& Koller, 2003; Mondin, 2008) quanto com problemas de comportamento nas crianças (Mondin, 2008; Vitolo, Fleitlich-Bilykb, Goodmanc, \& Bordin, 2005). Também foi reconhecido que, nas transições entre as diferentes fases do ciclo de vida familiar, são maiores as probabilidades de dificuldade de manejo parental (Augustin \& Frizzo, 2015; Carter \& McGoldrick, 1995). Por fim, a influência transgeracional das práticas parentais também está presente na literatura (Böing, 2014; Cecconello, Antoni, \& Koller, 2003; Oliveira et al, 2002; Weber, Selig, Bernardi, \& Salvador, 2006).

Na temática 1, após a apresentação da intervenção, todos os participantes demonstraram compreender o propósito do programa. Os objetivos elencados pelos pais durante a primeira temática podem ser divididos em três categorias: a) estabelecimento de rotina, regras e limites que funcionem dentro do ambiente familiar, uma vez que as abordagens utilizadas pelas famílias não eram eficazes; b) melhora nas relações e diminuição de conflitos familiares, pois havia agressões físicas e verbais ocorrendo dentro das famílias participantes; e c) auxílio para o manejo de comportamentos indesejados e/ou inapropriados das crianças.

No caso 1, foi observada a dificuldade do pai em estabelecer regras e tarefas com o filho, o excesso de punições e castigos, a necessidade de impor limites nos seus comportamentos desrespeitosos e o desejo de diminuir os conflitos constantes entre os dois. No caso 2, os pais explicaram seus problemas ao impor limites tanto à filha mais nova quanto ao filho mais velho, assim como a necessidade de organizar a família em torno de uma rotina com regras que permitisse um convívio familiar mais harmonioso. Os pais também pediram auxílio para aprender a lidar com as mudanças ocasionadas pela adolescência da filha do meio. No caso 3, foi verificada a necessidade de estabelecer uma rotina e regras adequadas à filha do casal, que, até o momento da intervenção, estava sofrendo punições e castigos desproporcionais às dificuldades apresentadas. O objetivo da intervenção foi adequar as práticas parentais dos pais para manejar os comportamentos mais difíceis da menina, diminuir os conflitos em casa e aumentar as interações positivas.

Já na temática 2, foi possível verificar a influência que as práticas parentais dos cuidadores dos participantes tiveram no desenvolvimento de suas próprias práticas parentais. Nos programas de treinamento de pais, baseados puramente na Terapia Cognitivo Comportamental pesquisados para a construção dessa intervenção (Caballo, 2005; Caminha \& Caminha, 2011; Pardo e Carvalho, 2012) não foi encontrado o aspecto de exploração do passado dos pais. O Propap estruturou um roteiro de sessão fundamentado na entrevista de apego adulto (Cassidy \& Shaver, 2008), cujo objetivo foi explorar as práticas parentais dos pais dos participantes do programa com o intuito de gerar insight sobre suas próprias práticas parentais, uma vez que a compreensão maior da própria infância pode levar a uma parentalidade melhor (Siegel, 2012).

Nos três casos analisados, os resultados apresentaram variação na eficácia da investigação do passado. No caso 1, ocorreu insight proveitoso para o pai; no caso 2, somente a mãe conseguiu relacionar seu passado com as práticas atuais, mesmo assim não produzindo mudanças; e, no caso 3 , a mãe só fez a conexão entre seu passado e as práticas parentais voltadas ao filho, mas não com relação à filha. Essa é uma limitação de intervenções curtas como a do Propap, em que não é possível desenvolver de forma mais ampliada a complexa tarefa de investigação do passado e relacioná-lo às práticas do presente.

Durante a temática 3 , foram analisadas a rotina, as regras e os limites que os pais estabeleciam com os filhos. Famílias saudáveis mantêm uma hierarquia clara e um respeito mútuo que permitem o estabelecimento de regras e limites entre seus membros. Isso, por sua vez, estrutura a rotina da família e auxilia na manutenção de um contexto que estimula o desenvolvimento das crianças (Cruz \& Lima, 2012; Ferriolli, Marturano, \& Puntel, 2007; Fishman, 1998; Minuchin \& Fishman, 1990). 
Após análise do trabalho realizado nos três casos dentro dessa temática, podemos verificar na família de pais separados do caso 1 que os problemas eram diferentes das famílias intactas dos casos 2 e 3 . No primeiro, os principais problemas identificados foram o excesso de rigidez e a imposição da rotina pelo pai, o descumprimento dela pelo filho e a tentativa de fazer a rotina funcionar por meio de recompensas monetárias. Foi trabalhada a construção de uma rotina em conjunto com o adolescente e a adoção de estratégias parentais mais adequadas, como retirada de privilégios e estabelecimento de recompensas. Essas estratégias de trabalho em conjunto e integração do adolescente na construção da rotina tinham por objetivo melhorar a relação entre pai e filho, pois são melhores preditoras de uma relação mais harmoniosa e sem comportamentos externalizantes do que as práticas coercitivas (Alvarenga, Magalhães, \& Gomes, 2012).

Nos casos 2 e 3, verificou-se que os principais problemas eram a sobrecarga de responsabilidade sobre a mãe e a falta de acordo entre os pais sobre o estabelecimento da rotina. Nesses casos, ficou evidente a falta de interesse paterno em se envolver nas rotinas da casa e na educação dos filhos, o que influencia diretamente no exercício da coparentalidade (Augustin \& Frizzo, 2015). Ainda se ressalta que ambos os homens da díade parental não tiveram uma relação próxima com suas mães ou seus pais. Essa informação é importante por dois motivos: a) a proximidade na relação entre o marido e sua mãe está correlacionada a uma percepção positiva da esposa sobre a comunicação e o funcionamento familiar; e b) a proximidade entre o marido e seu pai está correlacionada ao endosso da parentalidade da esposa, que, por sua vez, está relacionado a um uso menor de estratégias punitivas por ela (Böing, 2014). Apesar da psicoeducação, os problemas de coparentalidade não puderam ser propriamente endereçados, uma vez que seu escopo não estava abarcado na proposta de intervenção.

As temáticas 4 e 5 focaram em fazer os pais prestarem atenção naquilo que os filhos estavam fazendo de positivo, reforçando as práticas positivas do elogio e da recompensa, e em como lidar com os comportamentos negativos de forma adequada. Nas duas temáticas, foram discutidas maneiras alternativas de educar os filhos que promovessem um relacionamento familiar mais harmonioso e que proporcionassem um melhor desenvolvimento para as crianças.
Sob esse tema, os três casos apresentaram como características comuns: a) o uso de práticas parentais inadequadas, como punição corporal e ameaças; b) a dificuldade de empatizar com os problemas da criança; e c) expectativas incompatíveis com o estágio do desenvolvimento dos filhos. De acordo com as necessidades de cada família, foram construídas formas diferentes de compreender e de lidar com as crianças, de maneira que os pais aprendessem práticas mais adequadas, além de compreender e ter expectativas realistas para os filhos. Essa parte do trabalho é muito importante, uma vez que práticas parentais inadequadas, principalmente práticas coercitivas, têm grande impacto negativo no desenvolvimento das crianças (Patias, Siqueira, \& Dias, 2012).

Na última temática (Encerramento e avaliação da intervenção), foi retomado tudo o que foi visto no programa, sendo entregue um memorial com as estratégias abordadas. Também foi realizado um pequeno questionário sobre o que já havia se modificado na família, o que havia começado a mudar e aquilo que ainda não mudou, mas que poderia mudar no futuro a partir dos aprendizados da intervenção.

Os três casos apresentaram dois pontos importantes: todos tiveram os objetivos atingidos totalmente e, em parte, todas as famílias apresentavam problemas maiores que necessitavam de acompanhamento psicoterapêutico. Os três casos dividiram objetivos atingidos na área de regras, limites e rotina familiar, ou seja, a mudança da rotina da família e o estabelecimento de regras e limites provocou mudanças positivas nos núcleos. Dentre os objetivos que não foram atingidos ou foram atingidos parcialmente nos três casos, verificam-se os problemas de relacionamento entre pais e filhos, que extrapolam o objetivo da intervenção. Ainda assim, dois casos conseguiram atingir esses objetivos parcialmente, tendo algum reflexo positivo no relacionamento familiar. Todos apresentaram problemas de relacionamento familiar que necessitavam de acompanhamento psicoterapêutico, e apesar da intervenção do Propap não objetivar o tratamento dessas dificuldades, a orientação parental serviu de porta de entrada para o tratamento psicoterápico dessas famílias.

$\mathrm{Na}$ avaliação de resultados da intervenção do caso 1, foi observado que o esforço e o desempenho escolar do adolescente ainda não tinham melhorado. Apesar dessa observação, espera-se que, com a mudança nas práticas parentais, de um modelo punitivo para outro com ênfase na monitoria, na rotina 
e na comunicação positiva, o adolescente melhore o desempenho acadêmico (Salvador, 2007). No caso 2, somente o processo terapêutico poderá auxiliar o pai a atingir o objetivo de melhorar sua relação com o filho mais velho. $\mathrm{O}$ caso 3 considerou que todos os objetivos foram atingidos, pelo menos, em parte.

A temática livre dependia das necessidades de cada família, podendo ser ou não realizada, o que ocorreu somente no caso 2, em que houve psicoeducação sobre temperamento infantil e desregulação emocional. Os demais casos apresentaram algumas dificuldades pontuais que, apesar de não serem o foco da intervenção, acabaram sendo abarcadas por alguma das temáticas.

Além da avaliação com o terapeuta no encerramento do programa, todos os pais e cuidadores participantes preencheram um formulário anônimo de avaliação da intervenção, com espaço para realizar sugestões, elogios e críticas. As avaliações foram todas muito positivas, com destaque para os depoimentos de melhora nas dinâmicas familiares e para a solicitação de que o programa fosse mais extenso.

\section{Considerações finais}

A intervenção do Propap foi desenvolvida para auxiliar pais e cuidadores a desenvolver práticas parentais saudáveis e adequadas. Os casos relatados neste estudo evidenciam que muitas famílias compartilham dificuldades com relação à rotina, às regras e aos limites, e que uma intervenção breve que vise essas dificuldades pode auxiliar na melhora das relações familiares. Além disso, a intervenção pode estabelecer um contato inicial da família com um serviço de psicologia, incentivando a busca posterior por serviços que possam atender suas demais dificuldades. Uma das problemáticas que se mostrou frequente nos casos e exigiu o encaminhamento para psicoterapia de família foi a coparentalidade e a consequente divisão de tarefas entre os pais.

A análise qualitativa da aplicação do programa permitiu verificar que a exploração do passado dos pais estava sendo realizada muito cedo na intervenção, de maneira que o vínculo entre os participantes e o terapeuta poderia não estar suficientemente estabelecido para que revelações e insights importantes pudessem ocorrer. Nesse sentido, a temática de experiências dos pais e cuidadores foi realocada para ocorrer após a temática de práticas parentais e bons comportamentos nas próximas edições do programa.

Além do destaque acima, o estudo apresentou duas limitações importantes: a) não foi realizada uma medição antes e depois da intervenção que pudesse fornecer dados quantitativos sobre a eficácia do programa; e b) não foi realizada uma sessão de acompanhamento para verificar se as mudanças nas famílias foram duradouras. Essas duas limitações estão sendo endereçadas para a continuidade do programa. A equipe está buscando um instrumento que possa medir adequadamente a qualidade das interações familiares antes e depois da intervenção, bem como está sendo programada uma sessão de seguimento para avaliação da intervenção no longo prazo.

\section{Referências}

Alvarenga, P., Magalhães, M. O., \& Gomes, Q. S. (2012). Relações entre práticas educativas maternas e problemas de externalização em pré-escolares. Estudos de Psicologia, 29(1), 33-42. https://doi.org/10.1590/ S0103-166X2012000100004

Augustin, D., \& Frizzo, G. B. (2015). A coparentalidade ao longo do desenvolvimento dos filhos: Estabilidade e mudança no $1^{\circ}$ e $6^{\circ}$ ano de vida. Interação em Psicologia, 19(1), 13-24. http://dx.doi.org/10.5380/psi.v19i1.29239

Barkley, R. A. (2013). Defiant children:A clinician's manual for assessment and parent training (3a ed.). The Guilford Press.

Bjorklund, D. F., Yunger, J. L., Pellegrini, A. D. (2002). The evolution of parenting and evolutionary approaches to childrearing. In M. H. Bornstein (Ed.), Handbook of parenting (Vol. 2, pp. 3-30). Lawrence Erlbaum.

Blissett J. (2011). Relationships between parenting style, feeding style and feeding practices and fruit and vegetable consumption in early childhood. Appetite, 57(3), 826-31. https://doi.org/10.1016/j.appet.2011.05.318

Böing, E. (2014). Relações entre coparentalidade, funcionamento familiar e estilos parentais em uma perspectiva intergeracional [Tese de doutorado, Universidade Federal de Santa Catarina]. Repositório Institucional UFSC. https://repositorio.ufsc.br/bitstream/handle/123456789/128737/328440.pdf

Brandenburg, O. J., \&Weber, L. N. D. (2005). Revisão de literatura da punição corporal. Interação em Psicologia, 9(1), 91-102. http://dx.doi.org/10.5380/psi.v9i1.3289 
Breitenstein, S. M., Shane, J., Julion, W., \& Gross, D. (2015) Developing the eCPP: Adapting an evidence-based parent training program for digital delivery in primary care settings. Worldviews on Evidence-Based Nursing, 12(1), 31-40. https://doi.org/10.1111/wvn.12074

Caballo, V. E. (2005). Manual de psicologia clínica infantil e do adolescente: Transtornos Específicos. Santos.

Caminha, M. G., \& Caminha, R. M. (Org.) (2011). Intervenções e treinamento de pais na clínica infantil. Sinopsys.

Carter, B., \& McGoldrick, M. (1995). As mudanças no ciclo de vida familiar: Uma estrutura para a terapia familiar. Artes Médicas.

Cassidy, J., \& Shaver, P. R. (2008). The adult attachment interview: Protocol, method of analysis, and empirical studies. In J. Cassidy, \& P. R. Shaver (Eds.), Handbook of attachment: Theory, research, and clinical applications (2a ed., pp. 552-598). The Guilford Press.

Cecconello, A. M., Antoni, C., \& Koller, S. H. (2003). Práticas educativas, estilos parentais e abuso físico no contexto familiar. Psicologia em Estudo, 8(spe), 45-54. https://doi.org/10.1590/S1413-73722003000300007

Coatsworth, J. D., Duncan, L. G., Nix, R. L., Greenberg, M. T., Gayles, J. G., Bamberger, K. T., Berrena, E., \& Demi, M. (2015). Integrating mindfulness with parent training: Effects of the mindfulness-enhanced strengthening families program. Developmental Psychology, 51(1), 26-35. https://doi.org/10.1037/a0038212

Cruz, O., \& Lima, I. (2012). Qualidade do ambiente familiar: Preditores e consequências no desenvolvimento das crianças e jovens. Revista AMAzônica, 8(1), 244-263.

Ferriolli, S., Marturano, E., \& Puntel, L. (2007). Family context and child mental health problems in the Family Health Program. Revista de Saúde Pública, 41(2), 251-259. https://doi.org/10.1590/S0034-89102006005000017

Fishman, H. C. (1998). Terapia estrutural intensiva: Tratamento família em seu contexto social. Artes Médicas.

French, V. (2002). History of parenting: The Ancient Mediterranean world. In M. H. Bornstein (Ed.), Handbook of parenting (Vol. 2, pp. 345-376). Lawrence Erlbaum.

Goodman, R. (1997). The strengths and difficulties questionnaire: A research note. Journal of Child Psychology and Psychiatry, 38(5), 581-586. https://doi.org/10.1111/j.1469-7610.1997.tb01545.x

Henneberger, A. K., Varga, S. M., Moudy, A., \& Tolan, P. H. (2016). Family functioning and high risk adolescents' aggressive behavior: Examining effects by ethnicity. Journal of Youth and Adolescence, 45(1), 145-155. https://doi.org/10.1007/s10964-014-0222-8

Law, G. C., Neihart, M., \& Dutt, A. (2017). The use of behavior modeling training in a mobile app parent training program to improve functional communication of young children with autism spectrum disorder. Autism, 22(4), 424-439. https://doi.org/10.1177/1362361316683887

Lochman, J. E. (2016, 16-19 de junho). Does parent involvement matter when working with aggressive children? 20 International Congress Cognitive Behavioral Coaching, Atenas, Grécia. http://www.edlearning.it/proceedings/ moreinfo/20160616_index.pdf

McGoldrick, M., Gerson, R., \& Petry, S. (2012). Genogramas: Avaliação e intervenção familiar (3a ed.). Artmed.

Minuchin, S., \& Fishman, C. H. (1990). Técnicas de terapia familiar. Artes Médicas.

Mondin, E. M. C. (2008). Práticas educativas parentais e seus efeitos na criação dos filhos. Psicologia Argumento, 26(54), 233-244.

Muratori, P., Milone, A., Manfredi, A., Polidori, L., Ruglioni, L., Lambruschi, F., \& Lochman, J. E. (2017). Evaluation of improvement in externalizing behaviors and callous-unemotional traits in children with disruptive behavior disorder: A 1-year follow up clinic-based study. Administration and Policy in Mental Health and Mental Health Services Research, 44(4), 452-462. https:// doi.org/10.1007/s10488-015-0660-y

Oliveira, E. A., Marin, A. H., Pires, F. B., Frizzo, G. B., Ravanello, T., \& Rossato, C. (2002). Estilos parentais autoritário e democrático-recíproco intergeracionais, conflito conjugal e comportamentos de externalização e internalização. Psicologia: Reflexão e Crítica, 15(1), 1-11. https://doi.org/10.1590/S0102-79722002000100002

Pacheco, J. T. B., Silveira, L. M. O. B., \& Schneider, A. M. A. (2008). Estilos e práticas educativas parentais: Análise da relação desses construtos sob a perspectiva dos adolescentes. Psico, 39(1), 66-73.

Pardo, M. B. L., \& Carvalho, M. M. S. B. (2012). Grupos de orientação de pais: Estratégias para intervenção. Contextos Clínicos, 5(2), 80-87. https://dx.doi.org/10.4013/ctc.2012.52.02

Patias, N. D., Siqueira, A. C., \& Dias, A. C. G. (2012). Bater não educa ninguém! Práticas educativas parentais coercitivas e suas repercussões no contexto escolar. Educação e Pesquisa, 38(4), 981-996. https://doi.org/10.1590/ S1517-97022012000400013 
Patterson G. R., Chamberlain, P., \& Reid, J. B. (2016). A comparative evaluation of a parent-training program. Behavior Therapy, 47(6), 804-811. https://doi.org/10.1016/j.beth.2016.11.004

Poehlmann-Tynan, J., Gerstein, E. D., Burnson, C., Weymouth, L., Bolt, D. M., Maleck, S., \& Schwichtenberg, A. J. (2015). Risk and resilience in preterm children at age 6. Development and Psychopathology, 27(3), 843-858. https://doi.org/10.1017/S095457941400087X

Reppold, C., Pacheco, J., \& Hutz, C. (2005). Comportamento agressivo e práticas disciplinares parentais. In C. Hutz. (Org.), Violência e risco na infância e adolescência: Pesquisa e intervenção (pp. 9-42). Casa do Psicólogo.

Salvador, A. P. V. (2007). Análise da relação entre práticas educativas parentais, envolvimento com tarefas escolares, depressão e desempenho acadêmico de adolescentes [Dissertação de mestrado, Universidade Federal do Paraná]. Acervo Digital da UFPR. https:/ / acervodigital.ufpr.br/handle/ 1884/10602

Shaffer, A., Lindhiem, O., Kolko, D. J., \& Trentacosta, C. J. (2013). Bidirectional relations between parenting practices and child externalizing behavior: A cross-lagged panel analysis in the context of a psychosocial treatment and 3-year follow-up. Journal of Abnormal Child Psychology, 41(2), 199-210. https://doi.org/ $10.1007 / \mathrm{s} 10802-012-9670-3$

Shah, P. E., Clements, M., \& Poehlmann, J. (2011). Maternal resolution of grief after preterm birth: Implications for infant attachment security. Pediatrics, 127(2), 284-292. https://doi.org/10.1542/peds.2010-1080

Shah, R., Sobotka, S. A., Chen, Y.-F., \& Msall, M. E. (2015). Positive parenting practices, health disparities, and developmental progress. Pediatrics, 136(2), 318-326. https://doi.org/10.1542/peds.2014-3390

Siegel, D. J. (2012). The developing mind: How relationships and the brain interact to shape who we are (2a ed.). The Guilford Press.

Smokowski, P. R., Rose, R. A., Bacallao, M., Cotter K. L., \& Evans, C. B. R. (2017). Family dynamics and aggressive behavior in Latino adolescents. Cultural Diversity and Ethnic Minority Psychology, 23(1), 81-90. https://doi.org/10.1037/cdp0000080

Vitolo, Y. L. C., Fleitlich-Bilykb, B., Goodmanc, R., \& Bordin, I. A. S. (2005). Crenças e atitudes educativas dos pais e problemas de saúde mental em escolares. Revista Saúde Pública, 39(5), 716-724. https://doi.org/10.1590/ S0034-89102005000500004

Weber, L. N. D., Viezzer, A. P., \& Brandenburg, O. J. (2004). O uso de palmadas e surras como prática educativa. Estudos de Psicologia, 9(2), 227-237. https://doi.org/10.1590/S1413-294X2004000200004

Weber, L. N. D., Selig, G. A., Bernardi, M. G., \& Salvador, A. P. V. (2006). Continuidade dos estilos parentais através das gerações: Transmissão intergeracional de estilos parentais. Paidéia, 16(35), 407-414. https://doi.org/10.1590/ S0103-863X2006000300011

Woerner, W., Fleitlich-Bilyk, B., Martinussen, R., Fletcher, J., Cucchiaro, G., Dalgalarrondo, P., Lui, M., \& Tannock, R. (2004). The strengths and difficulties questionnaire overseas: Evaluations and applications of the SDQ beyond Europe. European Child \& Adolescent Psychiatry, 13(Suppl. 2), 47-54. https://doi.org/10.1590/ S0034-89102005000500004

Zahrt, D. M., \& Melzer-Lange, M. D. (2011). Aggressive behavior in children and adolescents. Pediatrics in Review, 32(8), 325-331. https://doi.org/10.1542/pir.32-8-325

\section{Mateus Rebelo Benites}

Extensionista do Centro Interdisciplinar de Pesquisa e Atenção à Saúde do Instituto de Psicologia da Universidade Federal do Rio Grande do Sul (UFRGS), Porto Alegre - RS. Brasil.

E-mail: mateus.benites@gmail.com

(1) https://orcid.org/0000-0002-6229-9736

\section{Giovanna Nunes Cauduro}

Doutoranda do Grupo de Estudo, Avaliação e Pesquisa em Avaliação Psicológica do Programa de Pós-Graduação em Psicologia da UFRGS, Porto Alegre - RS. Brasil.

E-mail: gncauduro@gmail.com

(1) https://orcid.org/0000-0002-0554-0562 


\section{Luciana Valiente Vaz}

Psicóloga formada pelo Instituto de Psicologia da UFRGS, Porto Alegre - RS. Brasil.

E-mail: luciana.valiente.v@hotmail.com

(1) https://orcid.org/0000-0003-4824-391X

\section{Érica Prates Krás Borges}

Mestranda do Núcleo de Estudos em Neuropsicologia Cognitiva do Programa de Pós-Graduação em Psicologia da UFRGS, Porto Alegre - RS. Brasil.

E-mail: ericapkb@hotmail.com

(1) https://orcid.org/0000-0003-4228-0867

\section{Thais Selau}

Doutoranda do Grupo de Estudo, Avaliação e Pesquisa em Avaliação Psicológica do Programa de Pós-Graduação em Psicologia da UFRGS, Porto Alegre - RS. Brasil.

E-mail: thaisselau@hotmail.com

(1) https://orcid.org/0000-0002-8805-4016

Denise Balem Yates

Psicóloga do Centro Interdisciplinar de Pesquisa e Atenção à Saúde do Instituto de Psicologia da UFRGS, Porto Alegre - RS. Brasil.

E-mail: denise.yates@ufrgs.br

(1) https://orcid.org/0000-0002-0879-9270

Endereço para envio de correspondência:

Centro Interdisciplinar de Pesquisa e Atenção à Saúde. Rua Ramiro Barcelos, 2777, sala 314, Bom Fim. CEP: 90035-007. Porto Alegre - RS. Brasil.

Recebido 13/03/2018

Aceito 10/05/2019

Received 03/13/2018

Approved 05/10/2019

Recibido 13/03/2018

Aceptado 10/05/2019

Como citar: Benites, M. R., Cauduro, G. N., Vaz, L. V., Borges, E. P. K., Selau, T., \& Yates, D. B. (2021). Orientação a Práticas Parentais: Descrição de um Programa de Intervenção Individual Breve. Psicologia: Ciência e Profissão, 41 (n.spe 3), 1-15. https:// doi.org/10.1590/1982-3703003192813

How to cite:Benites, M. R., Cauduro, G. N., Vaz, L. V., Borges, E. P. K., Selau, T., \&Yates, D. B. (2021). Parenting Practices Orientation: Description of a Brief Individual Intervention Program. Psicologia: Ciência e Profissão, 41 (n.spe 3), 1-15. https://doi.org/10.1590/1982-3703003192813

Cómo citar: Benites, M. R., Cauduro, G. N., Vaz, L. V., Borges, E. P. K., Selau, T., \& Yates, D. B. (2021). Orientación a Prácticas Parentales: Descripción de un Breve Programa de Intervención Individual. Psicologia: Ciência e Profissão, 41 (n.spe 3), 1-15. https://doi.org/10.1590/1982-3703003192813 